\title{
Highlight report: metabolism and toxicity by fumonisins
}

\author{
Gisela H. Degen ${ }^{1}$
}

Published online: 23 November 2015

(C) Springer-Verlag Berlin Heidelberg 2015

Recently, Wang et al. (2015) from Huazhong University in China have published a comprehensive review about metabolism and toxicity of fumonisins. Fumonisins are a group of mycotoxins that occur worldwide, mostly in corn (maize) and corn-based products, but have also been found in wheat, rice, wine, black tea, nuts and other food commodities (Logrieco et al. 2010; Marín et al. 2007; Martins et al. 2001; Zimmer et al. 2008). The most prevalent of the fumonisins, $\mathrm{FB}_{1}$, is known to exert toxicities in liver and kidney, but also in other organs of farm and laboratory animals (Voss et al. 2007). In highly exposed human populations, fumonisins are suspected risk factors for oesophageal and liver tumours, neural tube defects and cardiovascular problems (Riley et al. 2015; Stockmann-Juvala and Savolainen 2008; Voss et al. 2007). This spectrum of toxicities necessitates a better understanding of the underlaying mechanisms, not only for an improved risk assessment, but also for developing mechanism-based approaches to counteract the toxic potential of fumonisins.

Fumonisins inhibit ceramide synthase leading to disrupted sphingolipid metabolism [references in Wang et al. (2015)]. Most recently, disruption of sphingolipid metabolism has been shown to be an apical event in $\mathrm{FB}_{1}$-induced autophagic cell death in kidney cells (Yin et al. 2015). Moreover, fumonisins influence the immune status by increasing cytokine levels in experimental animals. In recent years, several in vitro and in vivo studies have identified oxidative stress as one of the mechanisms by which fumonisins can lead to adverse

Gisela H. Degen

degen@ifado.de

1 Leibniz Research Centre for Working Environment and Human Factors, TU Dortmund, IfADo - Ardeystr. 67, 44139 Dortmund, Germany effects such as hepatotoxicity, nephrotoxicity and cardiotoxicity (Wang et al. 2015). Moreover, the IARC has classified fumonisin $\mathrm{B}_{1}$ as possibly carcinogenic to humans (IARC 2002). Nevertheless, fumonisins have attracted relatively little attention in toxicological research. Currently, hepatotoxicity (Campos et al. 2014; Liu et al. 2014; Godoy et al. 2009, 2013, 2015; Schyschka et al. 2013; Schliess et al. 2014; Grinberg et al. 2014), nephrotoxicity (Yang et al. 2014; Yu et al. 2013; Early et al. 2013; Kitada et al. 2006; Ruíz-López et al. 2006; Bulacio and Torres 2013) and cardiotoxicity (Fujisawa et al. 2014; Maayah et al. 2014; Ferreiro et al. 2014; Rossato et al. 2013) represent cutting-edge topics in toxicology. Recently, lists of reference compounds have been recommended for establishment of in vitro systems of repeated dose toxicity (Jennings et al. 2014; Hengstler et al. 2014). Perhaps it may be advisable to include fumonisins into these sets of compounds because of their well-documented hepatotoxicity and kidney toxicity in animals, and evidence for human exposure from recent biomonitoring studies (Gerding et al. 2015; Riley et al. 2015; van der Westhuizen et al. 2013). The present review of Wang et al. (2015) represents a must-read to anyone interested in mycotoxins.

\section{References}

Bulacio RP, Torres AM (2013) Organic anion transporter 5 (Oat5) renal expression and urinary excretion in rats treated with cisplatin: a potential biomarker of cisplatin-induced nephrotoxicity. Arch Toxicol 87(11):1953-1962. doi:10.1007/s00204-013-1062-0

Campos G, Schmidt-Heck W, Ghallab A, Rochlitz K, Pütter L, Medinas DB, Hetz C, Widera A, Cadenas C, Begher-Tibbe B, Reif R, Günther G, Sachinidis A, Hengstler JG, Godoy P (2014) The transcription factor CHOP, a central component of the transcriptional regulatory network induced upon $\mathrm{CCl} 4$ intoxication in mouse liver, is not a critical mediator of hepatotoxicity. Arch Toxicol 88(6):1267-1280. doi:10.1007/s00204-014-1240-8 
Early RJ, Yu H, Mu XP, Xu H, Guo L, Kong Q, Zhou J, He B, Yang X, Huang H, Hu E, Jiang Y (2013) Repeat oral dose toxicity studies of melamine in rats and monkeys. Arch Toxicol 87(3):517-527. doi:10.1007/s00204-012-0939-7

Ferreiro SF, Vilariño N, Carrera C, Louzao MC, Santamarina G, Cantalapiedra AG, Rodríguez LP, Cifuentes JM, Vieira AC, Nicolaou KC, Frederick MO, Botana LM (2014) In vivo arrhythmogenicity of the marine biotoxin azaspiracid-2 in rats. Arch Toxicol 88(2):425-434. doi:10.1007/s00204-013-1115-4

Fujisawa N, Nakayama SM, Ikenaka Y, Ishizuka M (2014) TCDD induced chick cardiotoxicity is abolished by a selective cyclooxygenase 2 (COX 2) inhibitor NS398. Arch Toxicol 88(9): 1739-1748

Gerding J, Ali N, Schwartzbord J, Cramer B, Brown DL, Degen GH, Humpf HU (2015) A comparative study of the human urinary mycotoxin excretion patterns in Bangladesh, Germany, and Haiti using a rapid and sensitive LC-MS/MS approach. Mycotoxin Res 31:127-136. doi:10.1007/s12550-015-0223-9

Godoy P, Hengstler JG, Ilkavets I, Meyer C, Bachmann A, Müller A, Tuschl G, Mueller SO, Dooley S (2009) Extracellular matrix modulates sensitivity of hepatocytes to fibroblastoid dedifferentiation and transforming growth factor beta-induced apoptosis. Hepatology 49(6):2031-2043. doi:10.1002/hep.22880

Godoy P, Hewitt NJ, Albrecht U et al (2013) Recent advances in 2D and $3 \mathrm{D}$ in vitro systems using primary hepatocytes, alternative hepatocyte sources and non-parenchymal liver cells and their use in investigating mechanisms of hepatotoxicity, cell signaling and ADME. Arch Toxicol 87(8):1315-1530. doi:10.1007/s00204013-1078-5 (review)

Godoy P, Schmidt-Heck W, Natarajan K, Lucendo-Villarin B, Szkolnicka D, Asplund A, Björquist P, Widera A, Stöber R, Campos G, Hammad S, Sachinidis A, Chaudhari U, Damm G, Weiss TS, Nüssler A, Synnergren J, Edlund K, Küppers-Munther B, Hay DC, Hengstler JG (2015) Gene networks and transcription factor motifs defining the differentiation of stem cells into hepatocyte-like cells. J Hepatol 63(4):934-942. doi:10.1016/j. jhep.2015.05.013

Grinberg M, Stöber RM, Edlund K et al (2014) Toxicogenomics directory of chemically exposed human hepatocytes. Arch Toxicol 88(12):2261-2287. doi:10.1007/s00204-014-1400-x

Hengstler JG, Marchan R, Bolt HM (2014) Standard compounds for establishment of in vitro test systems. Arch Toxicol 88(12):20832084. doi:10.1007/s00204-014-1398-0

International Agency for Research on Cancer (IARC) (2002) Fumonisin B1. Some traditional herbal medicines, some mycotoxins, naphthalene and styrene. In: Monographs on the evaluation of carcinogenic risks to humans, vol 82. IARC, Lyon, pp 301-366. doi:10.1016/j.fct.2009.12.006

Jennings P, Schwarz M, Landesmann B, Maggioni S, Goumenou M, Bower D, Leonard MO, Wiseman JS (2014) SEURAT-1 liver gold reference compounds: a mechanism-based review. Arch Toxicol 88(12):2099-2133. doi:10.1007/s00204-014-1410-8 (review)

Kitada N, Takara K, Kishi H, Sakaeda T, Ohnishi N, Yokoyama T (2006) Oxaliplatin up-regulated the function and expression of P-glycoprotein/MDR1 in porcine kidney epithelial LLC-PK1 cells. EXCLI J 5:179-190. ISSN: 1611-2156

Liu A, Krausz KW, Fang ZZ, Brocker C, Qu A, Gonzalez FJ (2014) Gemfibrozil disrupts lysophosphatidylcholine and bile acid homeostasis via PPAR $\alpha$ and its relevance to hepatotoxicity. Arch Toxicol 88(4):983-996. doi:10.1007/s00204-013-1188-0

Logrieco A, Ferracane R, Visconti A, Ritieni A (2010) Natural occurrence of fumonisin B2 in red wine from Italy. Food Addit Contam Part A Chem Anal Control Expo Risk Assess 27(8):11361141. doi:10.1080/19440041003716547
Maayah ZH, Ansari MA, El Gendy MA, Al-Arifi MN, Korashy HM (2014) Development of cardiac hypertrophy by sunitinib in vivo and in vitro rat cardiomyocytes is influenced by the aryl hydrocarbon receptor signaling pathway. Arch Toxicol 88(3):725-738. doi:10.1007/s00204-013-1159-5

Marín S, Ramos AJ, Vázquez C, Sanchis V (2007) Contamination of pine nuts by fumonisin produced by strains of Fusarium proliferatum isolated from Pinus pinea. Lett Appl Microbiol 44(1):68-72

Martins ML, Martins HM, Bernardo F (2001) Fumonisins B1 and B2 in black tea and medicinal plants. J Food Prot 64(8):1268-1270

Riley RT, Torres O, Matute J, Gregory SG, Ashley-Koch AE, Showker JL, Mitchell T, Voss KA, Maddox JR, Gelineau-van Waes JB (2015) Evidence for fumonisin inhibition of ceramide synthase in humans consuming maize-based foods and living in high exposure communities in Guatemala. Mol Nutr Food Res. doi:10.1002/mnfr.201500499

Rossato LG, Costa VM, de Pinho PG, Arbo MD, de Freitas V, Vilain L, de Lourdes Bastos M, Palmeira C, Remião F (2013) The metabolic profile of mitoxantrone and its relation with mitoxantrone-induced cardiotoxicity. Arch Toxicol 87(10):1809-1820. doi:10.1007/s00204-013-1040-6

Ruíz-López JC, Figueroa-Soto CG and Valenzuela-Soto EM (2006) Manganese inactivation of renal betaine aldehyde dehydrogenase from swine. EXCLI J 5:140-149. ISSN: 1611-2156

Schliess F, Hoehme S, Henkel SG, Ghallab A, Driesch D, Böttger J, Guthke R, Pfaff M, Hengstler JG, Gebhardt R, Häussinger D, Drasdo D, Zellmer S (2014) Integrated metabolic spatial-temporal model for the prediction of ammonia detoxification during liver damage and regeneration. Hepatology 60(6):2040-2051. doi:10.1002/hep. 27136

Schyschka L, Sánchez JJ, Wang Z, Burkhardt B, Müller-Vieira U, Zeilinger K, Bachmann A, Nadalin S, Damm G, Nussler AK (2013) Hepatic 3D cultures but not 2D cultures preserve specific transporter activity for acetaminophen-induced hepatotoxicity. Arch Toxicol 87(8):1581-1593. doi:10.1007/s00204-013-1080-y

Stockmann-Juvala H, Savolainen K (2008) A review of the toxic effects and mechanisms of action of fumonisin B1. Hum Exp Toxicol 27:799-809 (review)

van der Westhuizen L, Shephard GS, Gelderbloom WCA, Torres O, Riley RT (2013) Fumonisin biomarkers in maize eaters and implications for human disease. World Mycotoxin J 6(3):232233 (review)

Voss KA, Smith GW, Haschek WM (2007) Fumonisins: toxicokinetics, mechanism of action and toxicity. Anim Feed Sci Technol 137:299-325 (review)

Wang X, Wu Q, Wan D, Liu Q, Chen D, Liu Z, Martínez-Larrañaga MR, Martínez MA, Anadón A, Yuan Z (2015) Fumonisins: oxidative stress-mediated toxicity and metabolism in vivo and in vitro. Arch Toxicol. doi:10.1007/s00204-015-1604-8 (review)

Yang Y, Liu H, Liu F, Dong Z (2014) Mitochondrial dysregulation and protection in cisplatin nephrotoxicity. Arch Toxicol 88(6):1249_ 1256. doi:10.1007/s00204-014-1239-1 (review)

Yin S, Guo X, Li J, Fan L, Hu H (2015) Fumonisin B1 induces autophagic cell death via activation of ERN1-MAPK8/9/10 pathway in monkey kidney MARC-145 cells. Arch Toxicol. doi:10.1007/s00204-015-1514-9

Yu M, Xue J, Li Y, Zhang W, Ma D, Liu L, Zhang Z (2013) Resveratrol protects against arsenic trioxide-induced nephrotoxicity by facilitating arsenic metabolism and decreasing oxidative stress. Arch Toxicol 87(6):1025-1035. doi:10.1007/s00204-013-1026-4

Zimmer I, Usleber E, Klaffke H, Weber R, Majerus P, Otteneder H, Gareis M, Dietrich R, Märtlbauer E (2008) Fumonisin intake of the German consumer. Mycotoxin Res 24(1):40-52. doi:10.1007/BF02985269 